\title{
NMDA receptors are essential for the acquisition, but not expression, of conditional fear and associative spike firing in the lateral amygdala
}

\author{
Ki A. Goosens ${ }^{1}$ and Stephen Maren ${ }^{1,2}$ \\ ${ }^{1}$ Department of Psychology, University of Michigan, Ann Arbor, Michigan 48109-1109, USA \\ ${ }^{2}$ Neuroscience Program, University of Michigan, Ann Arbor, Michigan 48109-1109, USA
}

Keywords: CPP, freezing, glutamate, long-term potentiation, rat

\begin{abstract}
We examined the contribution of $\mathrm{N}$-methyl-D-aspartate (NMDA) receptors (NMDARs) to the acquisition and expression of amygdaloid plasticity and Pavlovian fear conditioning using single-unit recording techniques in behaving rats. We demonstrate that NMDARs are essential for the acquisition of both behavioral and neuronal correlates of conditional fear, but play a comparatively limited role in their expression. Administration of the competitive NMDAR antagonist \pm -3-(2-carboxypiperazin-4-yl) propyl-1-phosphonic acid (CPP) prior to auditory fear conditioning completely abolished the acquisition of conditional freezing and conditional single-unit activity in the lateral amygdala (LA). In contrast, CPP given prior to extinction testing did not affect the expression of conditional single-unit activity in LA, despite producing deficits in conditional freezing. Administration of CPP also blocked the induction of long-term potentiation in the amygdala. Together, these data suggest that NMDARs are essential for the acquisition of conditioning-related plasticity in the amygdala, and that NMDARs are more critical for regulating synaptic plasticity and learning than routine synaptic transmission in the circuitry supporting fear conditioning.
\end{abstract}

\section{Introduction}

Pavlovian fear conditioning is a simple behavioral paradigm used to study the neural mechanisms underlying fear learning and memory (Maren, 1999, 2001; Fendt \& Fanselow 1999; LeDoux, 2000; Goosens \& Maren, 2002). In a typical experiment, animals learn to associate an innocuous conditional stimulus (CS) with an aversive unconditional stimulus (US). After a single CS-US pairing, the CS alone becomes capable of eliciting a number of conditional fear responses (CRs), including increases in heart rate, respiration and somatomotor immobility (i.e. freezing). These CRs may be measured in later sessions as a behavioral index of long-term memory for prior conditioning.

There is much interest in elucidating the neurotransmitter systems that underlie this form of associative learning. Because of the important and well-established role that $N$-methyl-D-aspartate receptors (NMDARs) play in behavioral and cellular models of associative learning in the hippocampus (Bliss \& Collingridge, 1993; Maren \& Baudry, 1995; Malenka \& Nicoll, 1999), a great deal of work has examined the contribution of NMDARs to Pavlovian fear conditioning. For example, blockade of NMDARs by intra-amygdala infusion of D,L-2-amino-5-phosphonovalerate (APV, a selective NMDAR antagonist) has been shown to severely attenuate the acquisition of conditional fear in Pavlovian fear conditioning paradigms (Miserendino et al., 1990; Campeau et al., 1992; Fanselow \& Kim, 1994; Maren et al., 1996; Gewirtz \& Davis, 1997; Fendt, 2001; Lee et al., 2001; Goosens \& Maren, 2003). Also, NMDAR-dependent longterm potentiation (LTP) has been reported in the amygdala (Gean et al., 1993; Maren \& Fanselow, 1995; Huang \& Kandel, 1998; Bauer et al.,

Correspondence: Dr S. Maren, ${ }^{1}$ Department of Psychology, as above.

E-mail: maren@umich.edu

Received 27 February 2004, revised 10 May 2004, accepted 25 May 2004
2002). Collectively, these results indicate that NMDAR activation may be important for the formation of the CS-US association during fear learning. However, intra-amygdala infusion of APV has also been shown to block the expression of conditioned fear (Maren et al., 1996; Lee \& Kim, 1998; Fendt, 2001; Lee et al., 2001), and APV has been shown to reduce cell excitability in the amygdala ( $\mathrm{Li}$ et al., 1995; Maren \& Fanselow, 1995). These studies suggest that APV may prevent fear learning by reducing the excitability of amygdala neurons, rather than by preventing associative learning per se. Indeed, APV blocks LTP only at concentrations that also reduce baseline synaptic transmission (Chapman \& Bellavance, 1992; Bauer et al., 2002; but see Mahanty \& Sah, 1999). Thus, the contribution of amygdaloid NMDARs to fear learning is far from unequivocal.

Although it is clear that NMDAR-mediated neurotransmission in the amygdala plays a critical role in fear learning, studies have demonstrated an important role for other amygdaloid receptors in Pavlovian fear conditioning. Pharmacological manipulation of either metabotropic glutamate receptors or AMPA receptors in the amygdala has been shown to modulate fear conditioning (Kim et al., 1993; Rogan et al., 1997; Walker \& Davis, 1997; Fendt \& Schmid, 2002; Rodrigues et al., 2002). Dopamine receptor antagonism in the amygdala has also been shown to attenuate fear conditioning (Greba \& Kokkinidis, 2000; Guarraci et al., 2000; Rosenkranz \& Grace, 2002). One might expect, then, that even in the absence of behavioral learning after fear conditioning under NMDAR blockade, amygdala neurons might exhibit spared associative plasticity mediated by non-NMDA receptors.

To further explore the role of NMDARs in fear learning, we systemically administered \pm 3 -(2-carboxypiperazin-4-yl) propyl-1phosphonic acid (CPP), a competitive NMDAR antagonist, to rats prior to fear conditioning or extinction testing, and examined the effects on conditional spike firing in the lateral nucleus of the amygdala (LA). 
We sought to determine whether neurons in LA would show spared plasticity after fear conditioning under NMDAR blockade, even in the absence of behavioral learning. We also investigated whether NMDAR antagonism would prevent the expression of CS-elicited spike firing in awake, behaving animals. To determine whether systemic administration of CPP affects synaptic plasticity in the amygdala, we also examined the effects of CPP on the induction of amygdaloid LTP.

\section{Materials and methods Subjects}

All subjects were adult male Long-Evans rats (380-600 g) obtained from a commercial supplier (Harlan Sprague-Dawley, Indianapolis, IN, USA). The rats were individually housed in conventional hanging plastic cages on a $14: 10 \mathrm{~h}$ light : dark cycle (lights on at $07.00 \mathrm{~h}$ ). Food and tap water were provided ad libitum. All rats were handled daily for at least 1 week prior to surgery. All procedures were approved by the University Committee on Use and Care of Animals (UCUCA) at the University of Michigan, and carried out in accordance with NIH guidelines.

\section{Single-unit recordings in awake rats}

For experiments requiring the implantation of single-unit recording probes, rats were anesthetized with sodium pentobarbital $(65 \mathrm{mg} / \mathrm{kg}$ i.p.), and administered atropine methyl nitrate $(0.4 \mathrm{mg} / \mathrm{kg}$ i.p. $)$ to prevent airway obstruction. After mounting in a stereotaxic apparatus (Kopf Instruments, Tujunga, CA, USA), the scalp was incised and retracted, and lambda and bregma were placed in the same horizontal plane. Small burr holes were drilled as necessary for placement of jeweler's screws and a multichannel recording probe aimed at the dorsal division of the LA $(3.1-3.3 \mathrm{~mm}$ posterior to bregma, 5.2$5.4 \mathrm{~mm}$ lateral to the midline, $6.0-6.4 \mathrm{~mm}$ ventral to dura). After positioning the electrodes, dental acrylic was applied to the skull to hold the probe in place, and the rats were returned to their home cages.

Single-unit recording probes were adapted from Quirk et al. (1995). Each probe consisted of a bundle of eight tungsten wires $(25 \mu \mathrm{m}$ diameter; California Fine Wire, Grover Beach, CA, USA) soldered to a 20-pin $(10 \times 2)$ connector (Mill-Max Manufacturing, Oyster Bay, NY, USA). The wires were inserted into a 28-gauge stainless steel cannula and affixed to the connector with dental acrylic. Immediately prior to implantation of the electrode, the wires were cut to approximately $1 \mathrm{~mm}$ of the cannula tip. The final position of the electrode was optimized by monitoring auditory-evoked discharges.

For each recording session, a headstage cable consisting of two four-channel operational amplifiers (TLC2274ACD; Texas Instruments, Dallas, TX, USA) in a unity-gain (source-follower) configuration was attached to the connector on the rat's head. The operational amplifiers were battery-powered ( $\pm 6 \mathrm{~V} \mathrm{DC}$ ). The cable was connected to a commutator, permitting rats to move freely within the chamber. Neuronal data were amplified $(10000 \times)$ and filtered $(0.6-$ $6 \mathrm{kHz}$ ) (Neuralynx, Tucson, AZ, USA) prior to acquisition with commercial software (DataWave Technologies, Longmont, CO, USA). Data were acquired during a 3 -s period $(0.5 \mathrm{~s}$ before, $2 \mathrm{~s}$ during and $0.5 \mathrm{~s}$ after each white noise presentation).

\section{Field potential recordings in anesthetized rats}

For experiments involving the induction of LTP, animals were anesthetized with urethane (1.6 g/ kg body weight injected i.p.), and placed in a stereotaxic apparatus on a feedback-regulated heating pad to maintain body temperature at $37^{\circ} \mathrm{C}$ (Cole-Parmer Instruments, Chicago, IL, USA). After leveling of the brain, the scalp was incised and retracted, and small burr holes were drilled for placement of a recording electrode in the basolateral amygdala (BLA; $3.3 \mathrm{~mm}$ posterior to bregma, $5.0 \mathrm{~mm}$ lateral to the midline, $6.0-8.0 \mathrm{~mm}$ ventral to dura) and a stimulating electrode in the ventral angular bundle (VAB; $6.3 \mathrm{~mm}$ posterior to bregma, $5.0 \mathrm{~mm}$ lateral to the midline, $6.0-8.0 \mathrm{~mm}$ ventral to dura). After lowering of the recording electrode, the stimulating electrode was slowly lowered and the animal was monitored for seizure activity. The ventral placements of the two electrodes were adjusted to maximize the amplitude of the evoked BLA field potentials. The stimulation intensity was then adjusted to elicit a field potential with an approximately $300 \mu \mathrm{V}$ short-latency (6-8 ms) negative component. Rats were injected with either SAL or CPP shortly after induction of anesthesia.

Field potential recordings were obtained using stimulating and recording electrodes made of Epoxylite-insulated stainless steel insect pins (size 00). Recording and stimulation surfaces were formed by removing $50 \mu \mathrm{m}$ and $200 \mu \mathrm{m}$ of insulation, respectively. A bipolar stimulating electrode, consisting of two insect pins separated by approximately $750 \mu \mathrm{m}$, was used to reduce current spread. A jeweler's screw affixed to the skull served as a reference electrode. After placement of the stimulating and recording electrodes, the VABevoked field potential (FP) was allowed to stabilize for 15-30 min. The stimulation intensity was adjusted to elicit an FP with an approximately $300 \mu \mathrm{V}$ negative component. The stimulation current did not differ between the two groups $\left(F_{1,7}=0.07, P>0.80\right.$; mean current for SAL, $820 \pm 51.5 \mu \mathrm{A}$; for $\mathrm{CPP}, 839 \pm 52.4 \mu \mathrm{A})$. For each rat, a 10-min baseline was collected (1 response every $20 \mathrm{~s} ; 0.05 \mathrm{~Hz}$ ) 50 min after injection of SAL or CPP. LTP was then induced by delivery of four high-frequency stimulation (HFS) trains, each separated by $5 \mathrm{~min}$. Each train consisted of 10 200-ms bursts of $100 \mathrm{~Hz}$ stimulation delivered at $1 \mathrm{~Hz}$ (for 200 total pulses per train). Responses were collected both during the 5-min periods between HFS and for $60 \mathrm{~min}$ after LTP induction (1 response every $20 \mathrm{~s} ; 0.05 \mathrm{~Hz}$ ).

\section{Fear conditioning}

A modified observation chamber $(30 \times 24 \times 40 \mathrm{~cm}$; MED-Associates, Burlington, VT, USA) was used for all training and testing. The chamber consisted of aluminum (two side walls) and Plexiglas (rear wall, ceiling and hinged front door), and was situated in a soundattenuating cabinet in an isolated room. The floor of the chamber consisted of 19 stainless steel rods (4 mm diameter) spaced $1.5 \mathrm{~cm}$ apart (centre-to-centre). The rods were wired to a shock source and solid-state grid scrambler (MED-Associates, Burlington, VT, USA) for the delivery of footshock USs. A speaker for delivering acoustic stimuli was mounted to a grating on one wall of each chamber.

Each conditioning chamber rested on a load-cell platform that recorded chamber displacement in response to the rat's motor activity. The output of the chamber's load-cell was amplified at a level that was previously determined to optimize the detection of freezing behavior. The load-cell amplifier output from the chamber was digitized at $5 \mathrm{~Hz}$ (yielding 300 observations per minute) and was continuously acquired on-line using DataWave software (DataWave Technologies). The average raw load-cell output across the first 1-min period of each session (prior to CS presentation) was used to quantify locomotor activity. Freezing was quantified by calculating the number of observations below a freezing threshold. Freezing was scored only if a rat was immobile for $1 \mathrm{~s}$ or longer; thus, freezing was scored only for 
five or more contiguous observations. For each session, the freezing observations were converted to a percentage of total observations.

Two environmental contexts were used for conditioning and testing. These contexts differed across olfactory, visual and auditory dimensions. For Context A, the chambers were cleaned with a 5\% ammonium hydroxide solution and stainless steel pans with a thin layer of the same solution were placed under the grid floor before the rat was placed in the chamber. The doors to the sound-attenuating cabinet remained open, and illumination was provided by both room lights and a small stimulus light $(15 \mathrm{~W})$ in the chamber. Ventilation fans in the cabinet supplied background noise ( $65 \mathrm{~dB}, \mathrm{~A}$-scale). All fear conditioning was conducted in Context A. For Context B, a 1\% acetic acid solution was used to clean the chamber and was placed in the pan under the grid floor. The sound-attenuating cabinet doors were closed. Illumination from dimmed computer screens and a $30 \mathrm{~W}$ red light permeated a small window on the cabinet door, and the ventilation fan and stimulus light were turned off. All extinction testing was conducted in Context B.

\section{Data analysis}

Single-unit data were analysed off-line using Experimenter's Workbench and Autocut software (DataWave Technologies), and Neuroexplorer software (NEX Technologies; Littleton, MA, USA). Single units were extracted from each channel using window discriminators and cluster analysis. Auto- and cross-correlograms were used to ensure that clusters corresponded to distinct single cells. Cluster boundaries were generated from the later recording sessions and applied to data from earlier sessions to ensure that the same units were analysed across sessions. For each cell within a session, the data were binned into 10 - or 50-ms bins across 10 trials, and the average bin size during the 500-ms pre-CS was calculated. Within each session and for each cell, all bins across the 3 -s recording period were normalized to this 500 -ms pre-CS average to create a $z$-score value for each bin. Thus, the $z$-score value of an individual bin was calculated as the difference between the raw bin value and the average raw bin value across the $500-\mathrm{ms}$ pre-CS period divided by the standard deviation of the average raw bin value across the $500-\mathrm{ms}$ pre-CS period. For each cell in each recording session, the $z$-score values were plotted to generate a peri-stimulus time histogram (PSTH) for each cell, and the average PSTH of all cells was calculated for each group during individual recording sessions. Cells were excluded if they failed to show CS responsivity (unit activity of $>3$ standard deviations above baseline in the first 50-ms bin after CS onset) in any session, or if the CS responsivity exceeded 30 standard deviations above baseline in the first 50-ms bin after CS onset.

For the acute electrophysiology experiment in anesthetized rats, field potentials were analysed off-line using Experimenter's Workbench (DataWave Technologies). Four parameters were analysed: the latency, amplitude and slope of the negative component peak, and the amplitude of the positive component peak.

\section{Drugs}

CPP (Sigma-Aldrich, St. Louis, MO, USA) was dissolved in $0.9 \%$ sterile saline $(10 \mathrm{mg} / \mathrm{mL})$ and administered i.p. at a dose of $10 \mathrm{mg} / \mathrm{kg}$.

\section{Histology}

All electrode placements were verified after the experimental sessions were completed. Rats were overdosed with sodium pentobarbital, and a small anodal current $(80 \mu \mathrm{A}, 10 \mathrm{~s})$ was passed through recording electrodes to aid in the identification of electrode placements. Rats were then perfused across the heart with $0.9 \%$ saline and $10 \%$ formalin. The brains were postfixed in $10 \%$ formalin $/ 30 \%$ sucrose for $48 \mathrm{~h}$. Coronal brain sections $(40-55 \mu \mathrm{m})$ were cut, and sections were stained with thionin to visualize cell bodies and electrode tracks.

\section{Results}

\section{Electrode placements}

Rats were implanted with multichannel recording electrodes aimed at LA. A total of 274 cells from 21 rats were included in the analyses. Rats received SAL or CPP prior to either the acquisition of auditory fear conditioning (ACQ) or the expression of learned fear during extinction testing (EXPR). This resulted in the following groups: ACQ-SAL ( $n=5$ rats, 59 cells), ACQ-CPP ( $n=5$ rats, 75 cells), EXPR-SAL ( $n=7$ rats, 78 cells) and EXPR-CPP ( $n=4$ rats, 62 cells). The electrode placements for these rats are summarized in Fig. 1. Electrode placements were localized to both the dorsolateral and ventromedial divisions of LA, and one placement was in the

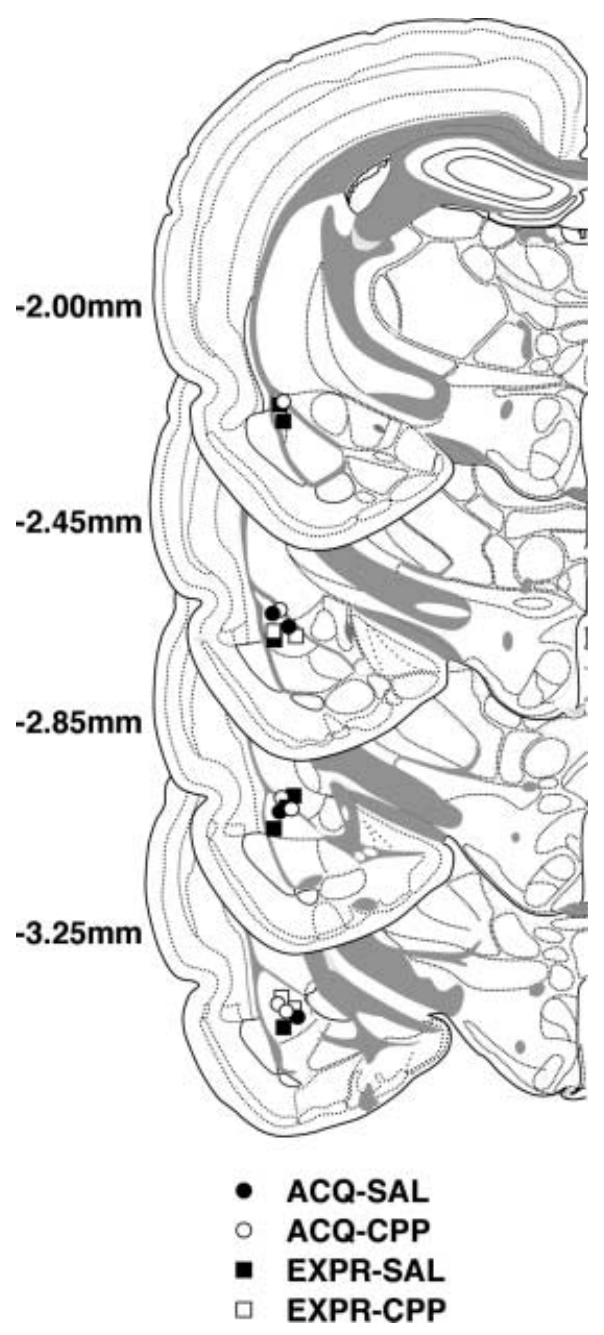

FIG. 1. Electrode placements in lateral amygdala. Schematic representation of the electrode placement for rats in the single-unit recording experiments. The numbers to the side of each section represent the distance of the section from bregma. The coronal sections were adapted from Swanson (1999). 
amygdalo-striatal termination zone, immediately adjacent to the dorsolateral LA.

\section{Effects of CPP on the acquisition of conditional freezing}

Three days after electrode implantation, rats underwent 3 days of fear conditioning and extinction testing (see Fig. 2 for an illustration of the behavioral paradigm). CS-evoked single-unit activity was recorded during each testing session, and freezing behavior was measured during all training and testing sessions. Each rat was first placed in a novel context (Context B) for a baseline recording session (PRE). During this session, the rats were presented with 10 white noise stimuli ( $2 \mathrm{~s}, 85 \mathrm{~dB}, 1 \mathrm{~min}$ ISI). Roughly 5 h later, rats received an i.p. injection of either SAL or CPP and, $1 \mathrm{~h}$ later, placed in the conditioning chamber (Context A). After $1 \mathrm{~min}$, rats received five co-terminating white noise $(2 \mathrm{~s}, 85 \mathrm{~dB})$-footshock $(1.0 \mathrm{~mA}, 0.5 \mathrm{~s})$ pairings ( $1 \mathrm{~min}$ ITI). Approximately $18 \mathrm{~h}$ later, the rats were placed in Context $\mathrm{B}$ for a second recording session (TEST 1) consisting of 10 white noise stimuli $(2 \mathrm{~s}, 85 \mathrm{~dB}, 1 \mathrm{~min}$ ISI). The effects of CPP on the acquisition of conditional fear were assessed by comparing freezing behavior and single-unit activity during the PRE and TEST 1 sessions. Five to six hours after the TEST 1 session, all rats were injected with SAL $1 \mathrm{~h}$ prior to placement in the conditioning chamber in Context A for a second training session consisting of five additional noise-footshock pairings. The following day, the rats were returned to Context $\mathrm{B}$ for a third and final recording session (TEST 2) consisting of 10 white noise presentations. Because fear conditioning and extinction testing were conducted in different contexts, freezing behavior and single-unit activity observed in the TEST 1 and TEST 2 sessions were expected to be related to fear associated with the auditory CS rather than contextual fear. By comparing freezing behavior and single-unit activity during the TEST 1 and TEST 2 sessions, we were able to determine whether any deficits observed during the TEST 1 session in the CPP group were due to an inability of the animals to condition, and whether the effects of the drug were time-limited.

Rats in both the SAL and CPP groups showed low levels of freezing during the 1-min period in the baseline recording session prior to fear conditioning (PRE; mean percentage of time spent freezing for SAL, $5.5 \pm 1.1 \%$, for CPP, $5.9 \pm 1.3 \%$ ). High levels of freezing behavior were observed during fear conditioning for both groups (Fig. 3A, left panel; minute, $\left.F_{4,28}=15.8, P<0.0001\right)$. Importantly, CPP did not produce an immediate post-shock freezing deficit during conditioning (group-minute interaction, $F_{4,28}=0.26$ ). In addition, the administration of CPP did not increase locomotor activity (data not shown; group, $F_{1,7}=0.90$, n.s.). Despite showing high levels of freezing during conditioning, rats in the CPP group demonstrated a massive deficit in conditional freezing during drug-free extinction testing
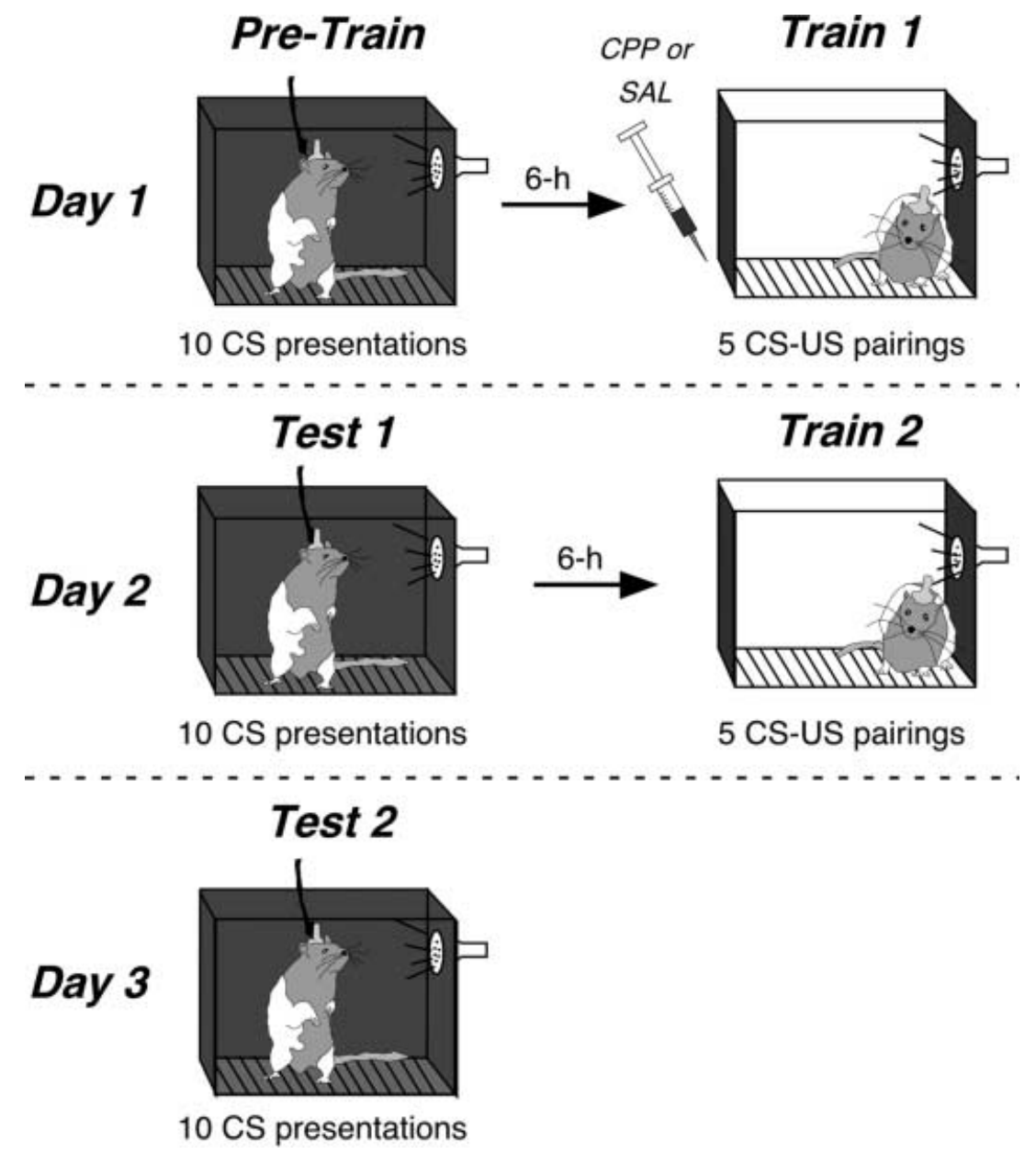

FIG. 2. Behavioral paradigm. Illustration of the procedure used to assess the effects of CPP on the acquisition of conditional fear. Note that all fear conditioning occurred in Context A, while all extinction testing occurred in Context B. 


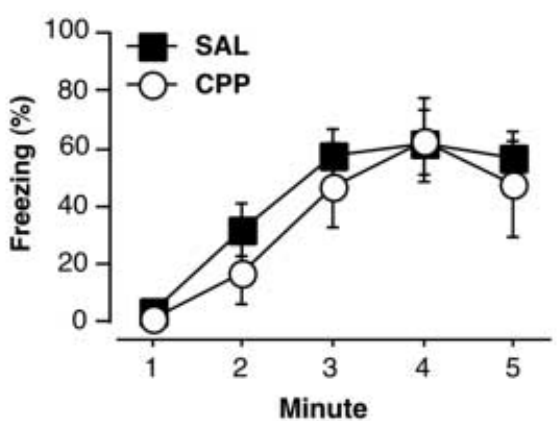

B

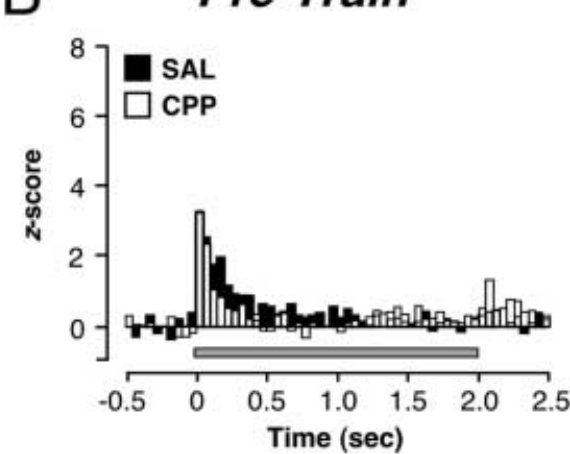

C

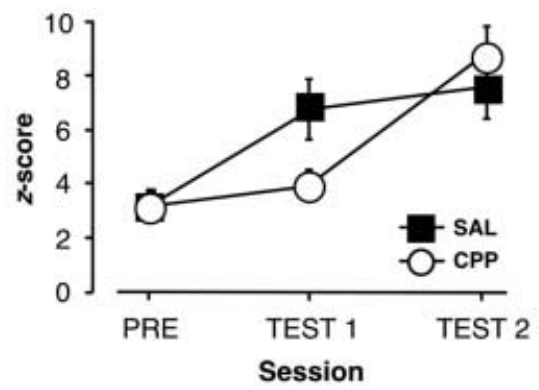

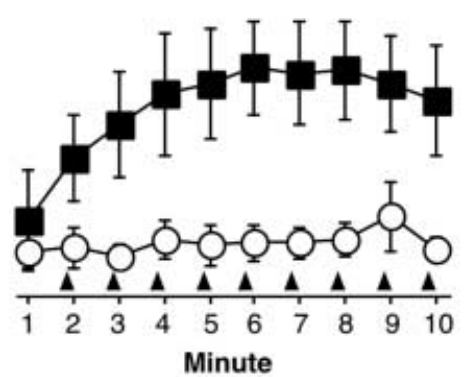

Test 1

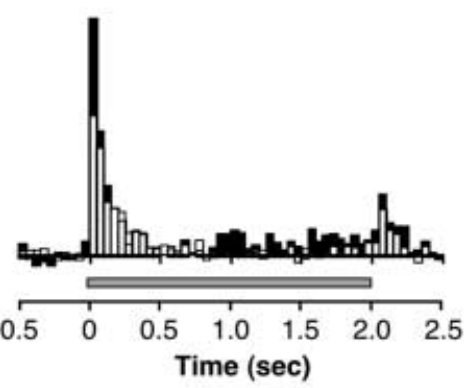

D $\quad S A L \quad C P P$

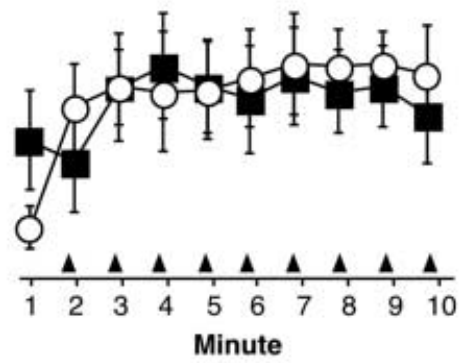

Test 2
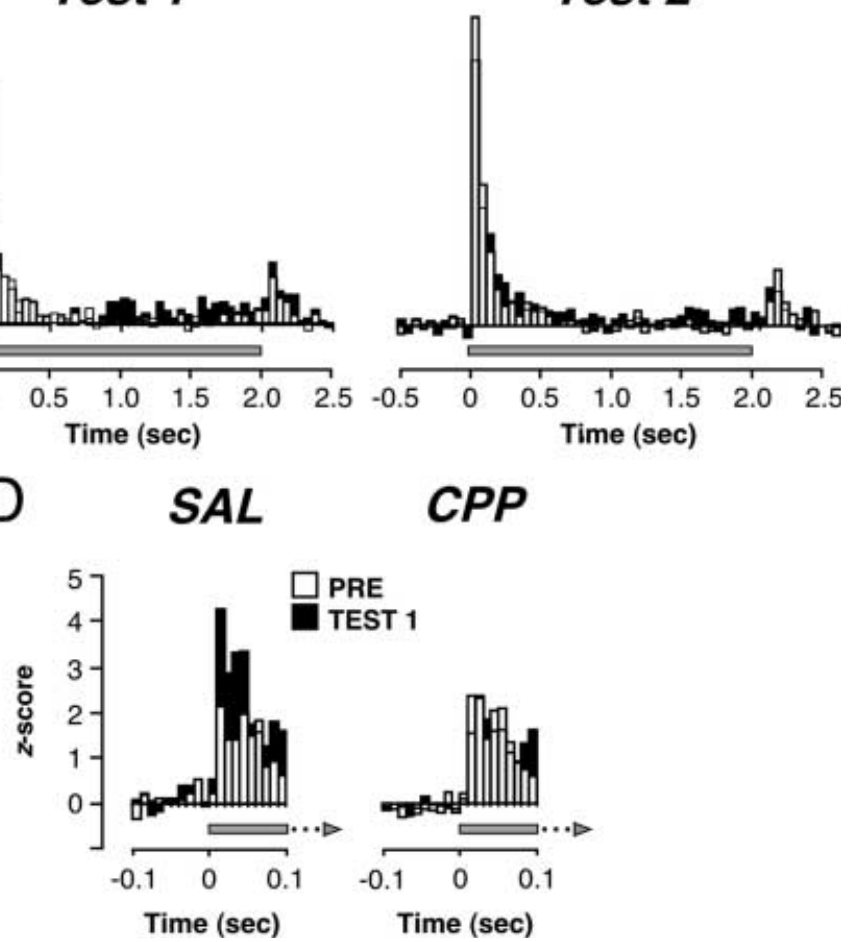

FIG. 3. Effects of CPP on the acquisition of conditional freezing and CS-evoked activity in LA. Baseline CS-evoked activity in LA was measured during a drug-free recording session (PRE), and rats were later injected with either SAL or CPP $1 \mathrm{~h}$ prior to auditory fear conditioning (TRAIN 1). CS-evoked activity in LA was assessed during two additional drug-free recording sessions occurring $12 \mathrm{~h}$ after the first (TEST 1) and second (TEST 2) fear conditioning sessions. Note that CPP was only administered before the first conditioning session (TRAIN 1) and was not present during any of the recording sessions. (A) The left panel depicts freezing behavior during auditory fear conditioning (TRAIN 1) in rats injected with SAL or CPP. The middle panel depicts the mean ( \pm SEM) percentage of time spent freezing during the $1 \mathrm{~min}$ prior to each CS presentation during the first extinction test (TEST 1). The right panel depicts the mean ( \pm SEM) percentage of time spent freezing during the 1-min period prior to each CS presentation during the second extinction test (TEST 2). Each point represents the mean ( \pm SEM) percentage of time spent freezing during the 1-min period prior to each CS presentation (indicated by filled triangles). (B) Average PSTHs (50-ms bins) representing spike firing for all CS-responsive cells recorded during each of the test sessions for rats injected with SAL or CPP prior to fear conditioning. Each bar represents the average normalized firing rate computed by summing spikes recorded for each cell during $10 \mathrm{CS}$ presentations and normalizing this activity in 50-ms bins after CS onset to the 500-ms pre-CS onset baseline; $z$-scores for each cell in the analysis were then averaged. The white bars represent the average response for cells from rats receiving CPP and the black bars represent the average response for cell from rats receiving SAL. The CS is indicated by grey line under the histogram. (C) Mean $z$-scores $( \pm$ SEM) in the first 50-ms bin following CS onset for each treatment group during the three recording sessions. (D) Average PSTHs (10-ms bins) representing spike firing for all CS-responsive cells recorded during each of the first two sessions for rats injected with SAL or CPP prior to fear conditioning. Each bar represents the average normalized firing rate computed by summing spikes recorded for each cell during 10 CS presentations and normalizing this activity in 10-ms bins after CS onset to the 500-ms pre-CS onset baseline; $z$-scores for each cell in the analysis were then averaged. The white bars represent the average response for cells from rats receiving CPP and the black bars represent the average response for cell from rats receiving SAL. The CS is indicated by a grey line under the histogram, and the arrow indicates that only the first $100 \mathrm{~ms}$ of the $2 \mathrm{~s}$ are shown.

(Fig. 3A, middle panel). This was revealed in the ANOvA by a significant main effect of group $\left(F_{1,9}=8.4, P<0.05\right)$ and a significant group-minute interaction $\left(F_{9,72}=2.1, P<0.05\right)$. Also, rats in the CPP group exhibited no conditional freezing during the first minute of TEST 1, prior to presentation of the first auditory CS. This suggests that there was little generalization between the conditioning and extinction contexts, and that the subsequent freezing and unit activity observed in these rats was attributable to fear of the auditory CS. Interestingly, CPP did not alter the post-conditioning increases in spontaneous firing rate that we and others (Rosenkranz \& Grace, 
2002; Goosens et al., 2003) have previously observed (data not shown; group, $F_{1,95}=0.24$, n.s.; group $\times$ session, $F_{1,95}=0.16$, n.s.). That is, the spontaneous firing rate of neurons increased between the PRE and PST1 sessions (session, $F_{1,95}=4.54, P=0.04$ ) for both the SAL and CPP groups. Thus, the administration of CPP prior to fear conditioning completely blocked the acquisition of long-term conditional fear memories, but did not affect either the expression of immediate post-shock freezing, an index of short-term memory (Kim et al., 1992), or the acquisition of conditioning-related changes in neuronal excitability.

To show that the absence of freezing in the CPP group was not due to amygdala damage from the electrode, both groups received additional drug-free fear conditioning trials and a second extinction test (TEST 2). As seen in Fig. 3A (right panel), rats in both groups demonstrated high levels of conditional freezing to the tone CS during the TEST 2 session (minute, $F_{9,72}=5.2, P<0.0001$ ). Rats in the CPP group demonstrated levels of conditional freezing that were similar to those of rats in the SAL group. This was confirmed in the ANOVA by a non-significant effect of group $\left(F_{1,9}=0.01\right.$, $P>0.90)$ and a non-significant group-minute interaction $\left(F_{9,72}=1.7, P>0.10\right)$. This suggests that the ability of CPP to prevent acquisition of conditional fear is time-limited, and the absence of conditional freezing in the CPP group during the TEST 1 session can be specifically attributed to the effects of CPP during fear conditioning.

\section{Effects of CPP on the acquisition of associative spike firing in LA}

Spontaneous activity of LA units $(n=134)$ was assessed during the $500-\mathrm{ms}$ pre-CS period in each of the 10 test trials during the PRE session. Units recorded from the SAL and CPP groups fired spontaneously at an average rate of $4.4 \mathrm{~Hz}$ (geometric mean $1.9 \pm 0.5 \mathrm{~Hz}$ ) with a range of $0.2-23.4 \mathrm{~Hz}$. The baseline firing rates of LA units did not differ between the two groups $\left(F_{1,95}=0.71\right.$, $P>0.40)$. These firing rates are similar to those previously reported for pyramidal neurons in LA (Quirk et al., 1995; Paré \& Gadreau, 1996; Repa et al., 2001). A unit was defined as CS responsive if firing in the first $50 \mathrm{~ms}$ after CS onset exceeded firing in the 500-ms pre-CS period by at least three standard deviations during at least one recording session. Using this criterion, 97 of 134 units $(72.4 \%)$ were CS responsive. The statistical analyses reported below are based on this population of CS responsive neurons.

As illustrated in Fig. 3B, fear conditioning produced substantial increases in short-latency CS-evoked spike firing (0-50 ms post-CS onset) in LA units for rats in the SAL group. In contrast, rats in the CPP group did not show significant increases in spike firing in this shortlatency bin (TEST 1). The mean $z$-score in the short-latency bin $(0-50 \mathrm{~ms})$ for each session and each group is depicted in Fig. 3C. An ANOVA performed on these data showed a significant group-session interaction $\left(F_{2,190}=3.8, P<0.05\right)$. Post-hoc comparisons $(P<0.05)$ revealed that rats in the SAL group showed a significant increase in spike firing in this bin from the PRE to TEST 1 session; however, rats in the CPP group did not show an increase across these sessions. When given five additional drug-free conditioning trials, conditional freezing to the CS reached similar levels in the SAL and CPP rats (Fig. 3B). Spike firing in the first $50 \mathrm{~ms}$ did not significantly increase for rats in the SAL group (Fig. 3C). This is consistent with other data demonstrating that associative spike firing is asymptotic after five conditioning trials (Maren, 2000). In contrast, rats in the CPP group showed significant increases in short-latency conditional spike firing (Fig. 3B and C), achieving levels similar to that observed in the SAL group.
After fear conditioning, CS-responsive units in LA exhibited plasticity as early as $10 \mathrm{~ms}$ after CS onset (Fig. 3D). This suggests that the plasticity observed in these neurons is localized to thalamic, rather than cortical, afferents (Quirk et al., 1995, 1997; Maren, 2000). Whereas rats in the SAL group showed a robust conditioning-related increase in CS-evoked spike firing in the second 10-ms bin after CS onset, rats injected with CPP prior to fear conditioning did not show significant increases in spike firing in any post-CS bin (Fig. 3D). The absence of any change in the spike firing profile during the first $100 \mathrm{~ms}$ after CS onset suggests that CPP completely blocked the acquisition of conditioning-related plasticity in LA. Together, these results demonstrate that administration of the competitive NMDAR antagonist CPP prior to auditory fear conditioning prevented the acquisition of both long-term conditional fear memory and associative spike firing in LA.

\section{Effects of CPP on the expression of conditional freezing}

A number of laboratories have demonstrated that pre-testing infusion of NMDAR antagonists into the BLA prevents the expression of previously learned fear responses (Maren et al., 1996; Lee \& Kim, 1998; Fendt, 2001; Lee et al., 2001; but see Miserendino et al., 1990). In addition, studies of amygdaloid plasticity in vitro have shown that NMDARs can play a role in regulating routine synaptic transmission (Chapman \& Bellavance, 1992; Gean et al., 1993; Maren \& Fanselow, 1995; Li et al., 1996). Thus, CPP may prevent the formation of conditional fear memories in LA by interfering with the transmission of CS and US information across the synapse rather than affecting associative mechanisms of fear learning. To examine this issue, we administered CPP to fear-conditioned rats prior to extinction testing to determine whether NMDAR antagonism interfered with the expression of conditional fear and associative plasticity in vivo.

The methods used were similar to those of the previous experiment (see Fig. 4 for an illustration of the behavioral paradigm). After implantation of a multichannel electrode aimed at LA, each rat was placed in a conditioning chamber in Context $\mathrm{B}$ for a baseline recording session (PRE). Roughly $6 \mathrm{~h}$ later, the rats were placed in a conditioning chamber (Context A). Rats received five co-terminating white noise $(2 \mathrm{~s}, 85 \mathrm{~dB})$-footshock $(1.0 \mathrm{~mA}, 0.5 \mathrm{~s})$ pairings $(1 \mathrm{~min}$ ITI) $1 \mathrm{~min}$ after placement in the chamber. Approximately $18 \mathrm{~h}$ later, all rats received an i.p. injection of $0.9 \%$ sterile saline (SAL). One hour after the injection, they were returned to Context $\mathrm{B}$ for a second recording session (TEST 1). Seven to nine hours after the TEST 1 session, rats were injected with SAL or CPP $1 \mathrm{~h}$ prior to placement in Context $\mathrm{B}$ for a second and final recording session (TEST 2). All recording sessions (PRE, TEST 1 and TEST 2) consisted of 10 white noise presentations $(2 \mathrm{~s}, 85 \mathrm{~dB}, 1 \mathrm{~min}$ ISI). The effects of CPP on the expression of conditional fear were assessed by comparing freezing behavior and single-unit activity during the TEST 1 and TEST 2 sessions.

Rats in both groups showed low levels of freezing prior to auditory fear conditioning (PRE) and a massive increase in the percentage of time spent freezing to the auditory CS after fear conditioning (TEST 1; Fig. 5A, left panel). It is clear that the levels of freezing observed did not differ between rats in the SAL and CPP groups during either of these sessions. A different pattern of results was obtained when the rats were injected with CPP prior to TEST 2. Whereas rats in the SAL group showed levels of conditional freezing that were similar to those observed in the first extinction session (TEST 1), rats in the CPP group showed an attenuation of conditional freezing (Fig. 5A, right panel). 


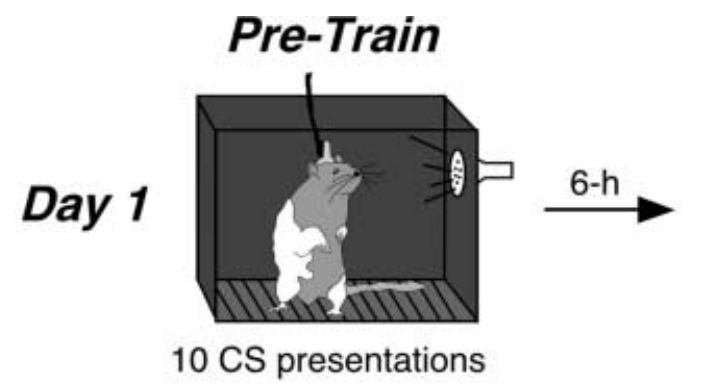

\section{Train}

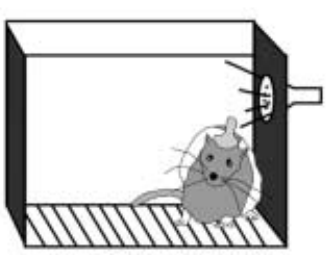

5 CS-US pairings

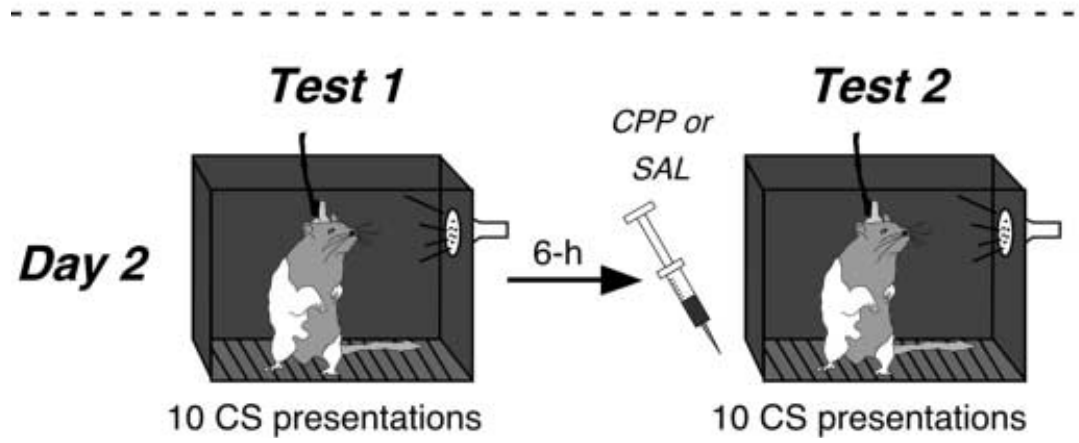

FIG. 4. Behavioral paradigm. Illustration of the procedure used to assess the effects of CPP on the expression of conditional fear. Note that all fear conditioning occurred in Context A, while all extinction testing occurred in Context B.

These observations were confirmed by a significant group-session interaction $\left(F_{2,20}=5.8, P<0.05\right)$ in the ANOvA, and by post-hoc comparisons $(P<0.05)$.

The percentage of time spent freezing in each minute between CS presentations during the second extinction test is depicted in the right panel of Fig. 5A. It is clear that the attenuation of freezing shown by rats in the CPP group can be attributed to slight decrements in conditional freezing relative to the SAL group throughout the extinction test, rather than a faster rate of extinction within the session. This was indicated in the ANOVA by a non-significant groupminute interaction $\left(F_{9,90}=0.99, P>0.40\right)$, suggesting CPP did not significantly affect the profile of the conditional freezing response. Moreover, it should be noted that rats injected with CPP prior to extinction testing did exhibit high levels of conditional freezing (approximately $71 \%$ at asymptote). Thus, the effect of CPP on the expression of conditional freezing was small when compared with the devastating effect of CPP on the acquisition of conditional freezing, or the effects of intra-amygdala infusion of the NMDAR antagonist APV. A similar pattern of results has been reported for the effects of CPP on the expression of bar-press suppression in response to fearful stimuli: systemic administration of CPP produced a mild attenuation of the expression of bar-press suppression and conditional freezing (Santini et al., 2001).

\section{Effects of CPP on the expression of associative spike firing in $L A$}

The firing properties of LA units $(n=140)$ recorded in this experiment were similar to those we reported for the previous experiment. The average spontaneous firing rate across both groups was $4.8 \mathrm{~Hz}$ (geometric mean $1.8 \pm 0.7 \mathrm{~Hz}$ ) with a range of $0.2-$ $44.6 \mathrm{~Hz}$, and there were no differences in baseline firing rates between the two groups $\left(F_{1,101}=0.12, P>0.70\right)$. Using the criterion we defined above, 103 of 140 units (73.6\%) were CS responsive, and the analyses reported below are based on these CS-responsive units.

Fear conditioning produced robust increases in short-latency CS-evoked spike firing (0-50 ms after CS onset) in LA units for rats in both groups (Fig. 5B, left panel, and $\mathrm{C}$ ). When rats were injected with SAL prior to the second extinction test (TEST 2), this conditional spike firing remained high (Fig. 5B, right panel). Rats that were injected with CPP prior to the second extinction test also expressed short-latency conditional spike firing (Fig. 5B, right panel). An ANOvA on these data (Fig. 5C) revealed a significant main effect of session $\left(F_{2,202}=13.3, \quad P<0.0001\right)$, but a non-significant effect of group $\left(F_{1,101}=0.31, P>0.50\right)$ and a non-significant group-session interaction $\left(F_{2,202}=0.18, P>0.80\right)$. Post-hoc comparisons confirmed that spike firing was significantly higher after conditioning (TEST 1 or TEST 2 compared with PRE), and that the two groups did not differ from each other on this measure in any session.

Although our results suggest that CPP does not affect the expression of conditional spike firing in LA, it is possible that CPP could modulate CS-elicited spike firing in a subtle manner. For example, it has been reported that NMDA receptors contribute more to excitatory responses elicited by thalamic compared with cortical afferents (Li et al., 1996; Weisskopf \& LeDoux, 1999). To address this, we compared spike firing in CPP-treated rats during TEST 1 and TEST 2 using 10-ms bins; this analysis can discriminate firing driven by thalamic (10-20 ms post-CS onset) and cortical (30-40 ms after CS onset) afferents. As shown in Fig. 5D, CPP administration during TEST 2 shifted the peak of the conditional activity by $20 \mathrm{~ms}$ relative to SAL administration in the same rats during TEST 1. Spike firing during TEST 2 peaked in the fourth post-CS onset bin (30-40 ms after CS onset) compared with a peak in the second postCS onset bin (10-20 ms after CS onset) during TEST 1. This shift was not observed in the SAL group; the peak bin remained the same 


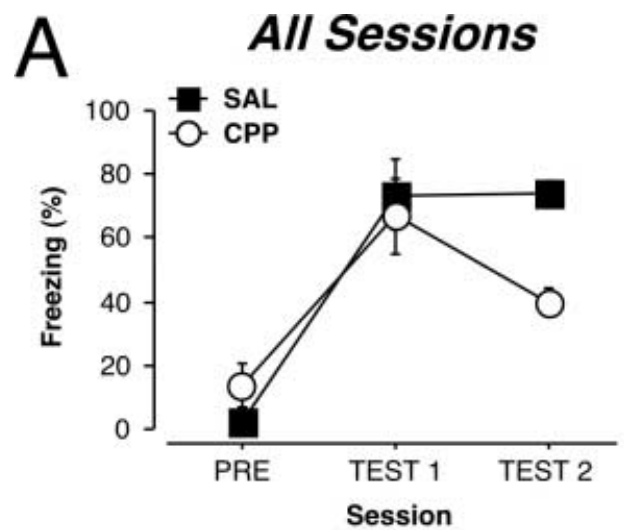

B
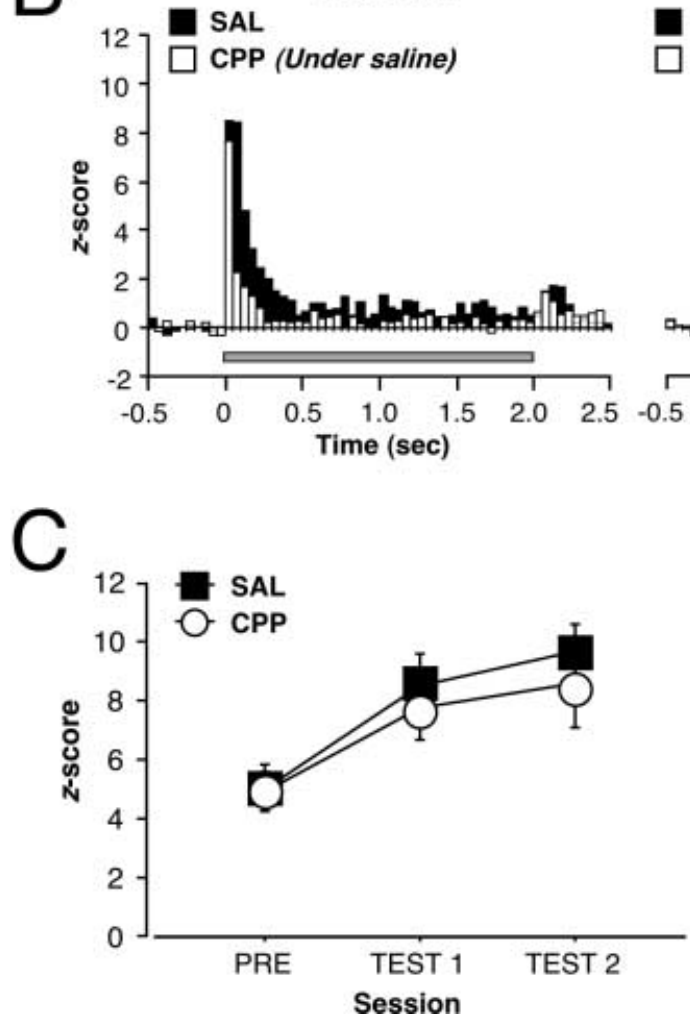

Test 2

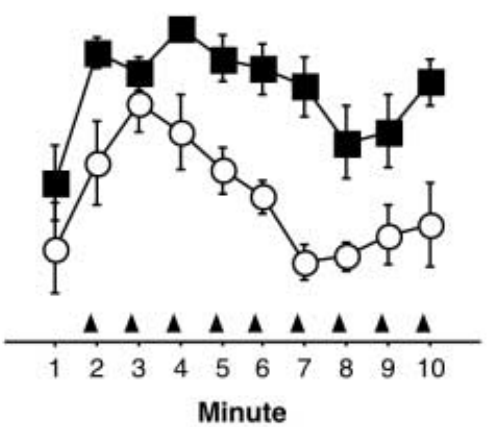

Test 2
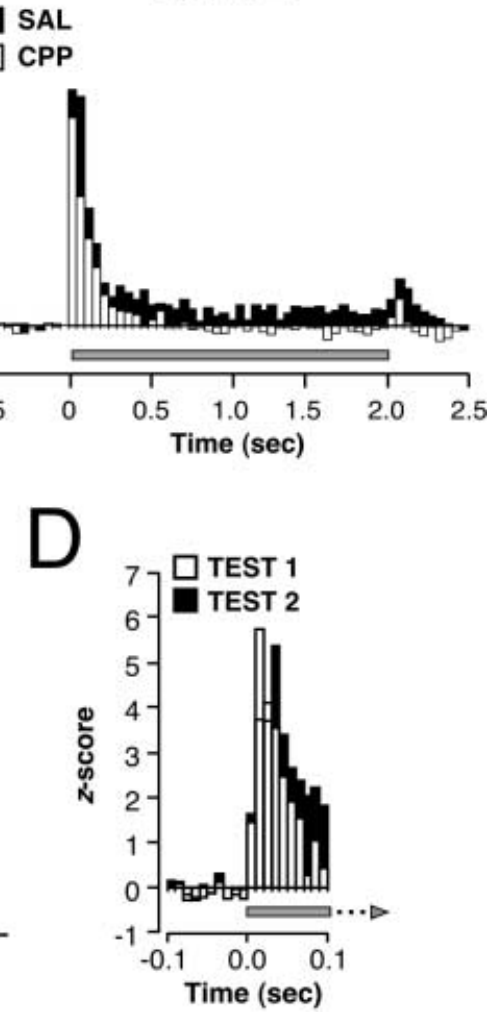

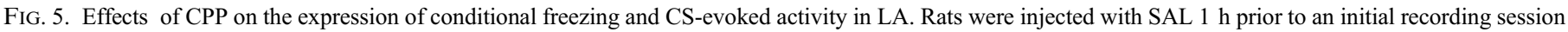

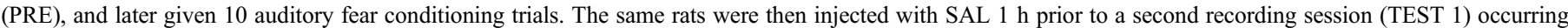

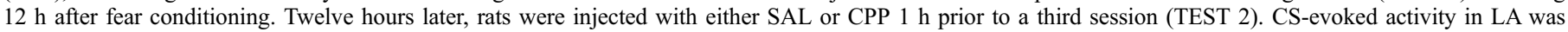

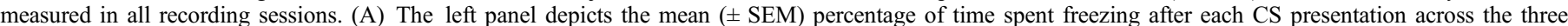

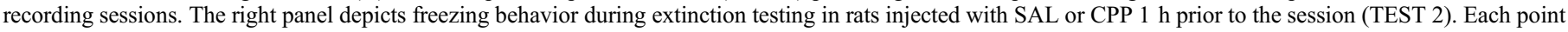

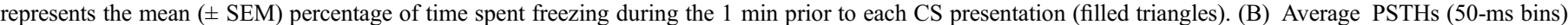

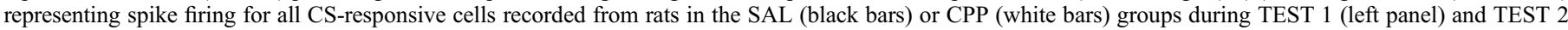

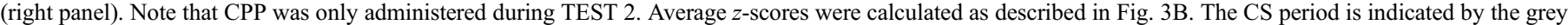

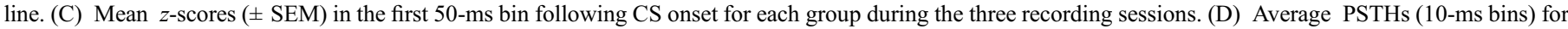

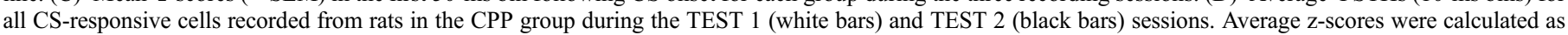
described in Fig. 3D. The presence of the CS is indicated by a grey line, and the arrow indicates that only the first 100 ms of the $2 \mathrm{~s}$ are shown.

between the TEST 1 and TEST 2 sessions (data not shown, also see Fig. 3D).

These data demonstrate that the administration of CPP prior to extinction testing of an auditory CS attenuates conditional freezing, but leaves the expression of associative increases in CS-evoked spike firing in LA largely intact. Our observations are similar to those previously reported for both bar-press suppression and conditional freezing (Santini et al., 2001). Together, our experiments suggest that amygdaloid NMDARs play a more limited role in mediating basal synaptic transmission in vivo than in the acquisition of the associative plasticity underlying conditional fear memory.

\section{Effects of CPP on the induction of amygdaloid LTP}

Because of the important role of amygdaloid NMDARs in fear memory and the acquisition of conditional plasticity in the LA, it was 

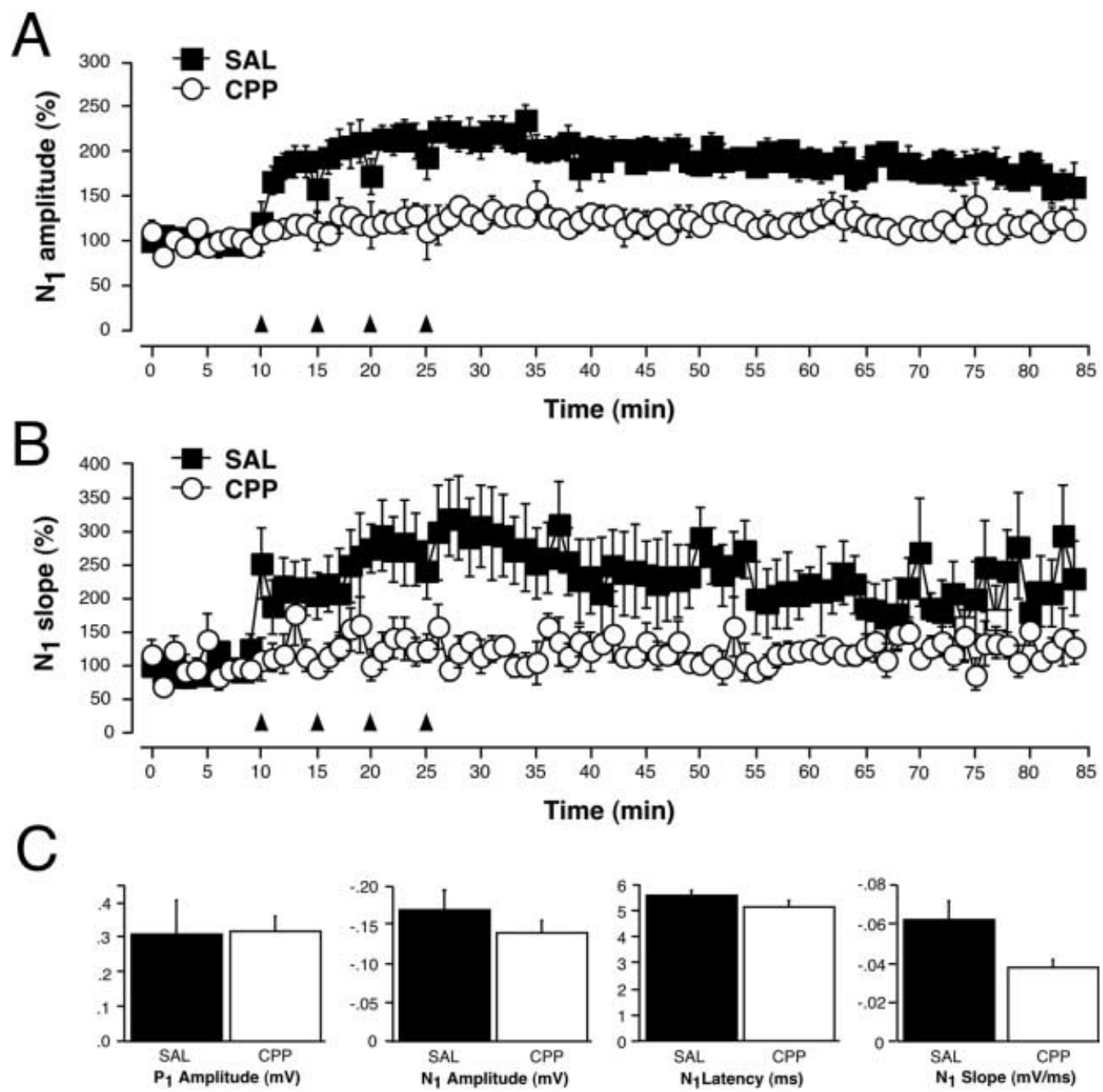

FIG. 6. Effects of CPP on the induction of LTP in the amygdala. Anesthetized rats were implanted with a stimulating electrode in the VAB and a recording electrode in the BLA. Rats were injected with SAL or CPP $1 \mathrm{~h}$ prior to the induction of LTP. After recording a 10-min baseline of evoked responses to single pulse stimulation, four trains of HFS were administered (indicated by arrows). Evoked responses to single pulse stimulation were recorded for $1 \mathrm{~h}$ after the last train of HFS. (A) Amplitude of the negative component of the evoked response $\left(\mathrm{N}_{1}\right.$, normalized to the average during the 10 min baseline). (B) Slope of the negative component of the evoked response $\left(\mathrm{N}_{1}\right.$, normalized to the average during the 10 min baseline). In both $\mathrm{A}$ and $\mathrm{B}$, each point represents a 1 min average of three evoked responses. (C) Effects of CPP on the amplitude of the positive component of the VAB-evoked FP $\left(\mathrm{P}_{1}\right)$, and the amplitude, latency and slope of the negative component of the VAB-evoked FP $\left(\mathrm{N}_{1}\right)$.

of interest to determine whether systemic administration of CPP was capable of affecting local synaptic plasticity in the amygdala. To examine this, we explored the effects of systemic administration of CPP on the induction of amygdaloid LTP in anesthetized rats.

Nine rats were included in the statistical analyses (SAL, $n=5$; CPP, $n=4)$. Four rats were excluded because of incorrect electrode placement, and two rats died before the end of the recording session. The rats that are included in the analyses had electrode placements similar to those in other published reports (Maren \& Fanselow, 1995). Recording electrodes were localized to the BLA, and stimulating electrodes were centred in the VAB, a source of excitatory hippocampal efferents to the amygdala.

As previously reported (Maren \& Fanselow, 1995), the VABevoked FP consisted of both a short-latency negative component $\left(\mathrm{N}_{1}\right)$ and a longer latency positive component $\left(\mathrm{P}_{1}\right)$. HFS increased both the amplitude (Fig. 6A) and slope (Fig. 6B) of $\mathrm{N}_{1}$ in the SAL controls. In contrast, the administration of CPP prior to the delivery of HFS prevented the induction of amygdaloid LTP: the amplitude and slope of $\mathrm{N}_{1}$ were unaffected by HFS. These results were confirmed in the ANOVA by significant main effects of time (amplitude, $F_{84,588}=17.5$, $P<0.0001$; slope, $F_{84,588}=4.8, P<0.0001$ ), and significant grouptime interactions (amplitude, $F_{84,588}=3.2, \quad P<0.0001$; slope, $\left.F_{84,588}=1.9, P<0.0001\right)$. Post-hoc comparisons $(P<0.05)$ on 10 -min averages after the last train of HFS was delivered revealed that the two parameters were not changed relative to baseline at any point in CPP-treated rats. HFS did not change either the latency of the $\mathrm{N}_{1}$ peak or the peak amplitude of $\mathrm{P}_{1}$ in either group (data not shown). This observation is consistent with published findings (Maren \& Fanselow, 1995).

To examine whether the administration of CPP altered baseline synaptic transmission within the amygdala, we compared the mean evoked response (averaged over the 10-min baseline period) for the SAL and CPP groups across the four measures reported above (Fig. 6C). The amplitude and latency of the peak of $\mathrm{N}_{1}$ did not differ between the two groups (amplitude, $F_{1,7}=0.81, P>0.40$; latency, $\left.F_{1,7}=1.9, P>0.20\right)$. The amplitude of $\mathrm{P}_{1}$ also did not differ between 
the groups $\left(F_{1,7}=0.01, P>0.90\right)$. However, there was a trend towards a significant difference between the SAL and CPP groups on the initial slope of $\mathrm{N}_{1}\left(F_{1,7}=4.1, P=0.08\right)$; rats in the SAL group exhibited a slightly greater slope than rats in the CPP group. Together, these data reveal that systemically administered CPP is capable of affecting local amygdaloid synaptic plasticity without significantly affecting baseline synaptic transmission.

\section{Discussion}

We have examined the influence of the competitive NMDAR antagonist CPP on the acquisition and expression of conditional fear and associative spike firing in LA, and assessed the effects of systemic CPP on the induction of LTP in the amygdala. Previous studies examining the effects of NMDAR antagonism on amygdaloid neuroplasticity have utilized anesthetized (Maren \& Fanselow, 1995) or slice (Chapman \& Bellavance, 1992; Li et al., 1995) preparations. However, we are the first to characterize the effects of NMDAR antagonism on spike firing in the amygdala of awake, behaving animals.

We chose to administer CPP systemically to avoid the technical difficulties associated with infusing into and recording from the same target brain area. Also, systemic administration of CPP has been used successfully to examine the contribution of NMDARs to place cell mapping in the hippocampus (Kentros et al., 1998) and, importantly, the contribution of NMDARs to the extinction of fear learning (Santini et al., 2001). Whereas the systemic administration of other NMDAR antagonists such as MK-801 produces marked alterations in behavior (e.g. Andine et al., 1999), we observed only a mild ataxia (slight difficulty with balance) after administration of CPP. Importantly, CPP did not produce the hyperactivity that accompanies the systemic administration of MK-801 or other NMDAR antagonists.

We observed that the administration of CPP prior to auditory fear conditioning completely abolished the acquisition of conditional freezing behavior and prevented conditioning-related changes in LA spike firing. This finding is consistent with other published reports demonstrating that preconditioning infusion of other NMDAR antagonists into the basolateral complex of the amygdala (consisting of the lateral and basolateral nuclei of the amygdala) produces profound behavioral deficits in conditional fear (e.g. Miserendino et al., 1990; Maren et al., 1996). The absence of any conditioning-related changes in CS-evoked spike firing observed here confirms the absence of 'savings', or learning not reflected in behavior, after fear conditioning under NMDAR blockade (Goosens \& Maren, 2003). These results provide further evidence that NMDAR-independent forms of plasticity in LA (e.g. Chapman et al., 1990; Weisskopf et al., 1999; Bauer et al., 2002) are insufficient to support the acquisition of long-term fear memories, and support a recent model of the cellular mechanisms mediating fear learning (Blair et al., 2001). According to this model, AMPA receptors and voltage-gated calcium channels transform NMDAR-mediated signals to a long-term memory trace. Thus, this model predicts that NMDAR blockade by CPP should prevent long-term plasticity in the amygdala. Interestingly, we observed that CPP left short-term memory, as indexed by immediate post-shock freezing in the conditioning session, intact. This pattern of results has been observed with both ICV administration of APV (Kim et al., 1991) and after intra-amygdala administration of APV (Lee \& Kim, 1998; but see Maren et al., 1996). NMDAR-independent forms of plasticity, then, may be sufficient to support immediate post-shock freezing in some cases.

CPP given prior to extinction testing caused a small but significant attenuation of overall conditional freezing, likely due to the mild motor impairments we observed, but left conditional unit activity in LA remarkably intact. A fine-grained analysis of spike firing revealed that although CPP did not affect overall spike firing within the first $50 \mathrm{~ms}$ of CS onset, the peak of the conditional response shifted from the second to the fourth post-CS onset bin (from 10 to $20 \mathrm{~ms}$ to 30-40 ms after CS onset), suggesting that systemic administration of CPP altered synaptic transmission within the LA. However, because conditional freezing was expressed at high levels by rats injected with CPP, it would appear that longer latency conditional responses in LA (30-40 ms after CS onset) are sufficient to drive a substantial level of conditional fear during extinction. Nonetheless, it is of interest that CPP reduced conditional spike firing only in the shortest latency bins following the CS. It is possible that this is due to the differential dependence of cortical and thalamic afferents on NMDARs. Thalamic afferents to the amygdala rely more heavily on the NR2A and $2 \mathrm{~B}$ subunits than auditory cortex afferents (Li et al., 1996; Weisskopf \& LeDoux, 1999). Hence, CPP may have selectively suppressed transmission in the thalamo-amygdala pathway. Amygdaloid plasticity driven by cortical afferents necessarily has a longer latency than that driven by thalamic afferents; the peak of the cortical response is 30$40 \mathrm{~ms}$ after CS onset (Quirk et al., 1997), which is considerably longer than the 10-20 ms latency observed in auditory thalamus (Quirk et al., 1995). Our observation that the peak of the conditional response in LA shifts to a longer latency (30-40 ms after CS onset) when extinction testing is conducted after administration of CPP is consistent with this possibility. If CPP indeed preferentially affects the thalamo-amygdala pathway, our results suggest that this pathway is necessary for the acquisition, but not expression, of conditional fear. In contrast, Romanski \& LeDoux (1992) reported that lesions of either the thalamo-amygdala or cortico-amygdala pathway did not disrupt the acquisition of conditional fear; however, this study used permanent lesions. The results here suggest that the intact rodent brain preferentially relies upon thalamic afferents to establish long-term fear memories in the amygdala.

The pattern of results we have observed in the present study is considerably different from those obtained with intra-amygdala infusion of APV, another competitive NMDAR antagonist. Intraamygdala infusion of APV prior to extinction testing produces massive deficits in the expression of conditional fear (Maren et al., 1996; Fendt, 2001; Lee et al., 2001). APV also severely attenuates synaptic transmission in the amygdala (Li et al., 1995; Maren \& Fanselow, 1995), and blocks baseline synaptic transmission at concentrations that do not affect the induction of LTP (Chapman \& Bellavance, 1992). There are several possible explanations for these discrepancies. One possibility is that intra-amygdala application of APV yields a higher concentration of drug than systemic administration of CPP. However, because APV is able to prevent baseline synaptic transmission without affecting the induction of LTP at some concentrations, it is likely that lower doses of APV would continue to affect the expression of conditional fear rather than mimicking the effects of CPP.

Alternatively, the different actions of CPP and APV could be explained by the observation that CPP is more selective for the NR2A and NR2B subunits of the NMDAR than APV (Hrabetova \& Sacktor, 1997), which does not show a subunit preference (Watkins \& Olverman, 1987). In addition, CPP has a greater affinity for the NR2A and 2B subunits than APV (Hrabetova \& Sacktor, 1997). Our results suggest, then, that a selective blockade of NMDARs containing the NR2A and 2B subunits impairs the acquisition but not expression of conditional fear. Similar to our results, it has been shown that intraamygdala blockade of the NR2B subunit attenuates the acquisition but not expression of conditional freezing (Rodrigues et al., 2001). In both cases, it would appear that NMDARs containing NR2A or 2B subunits are not required for immediate post-shock freezing or the expression 
of conditional freezing during extinction. Rather, these may depend on other NMDAR subunits, or non-NMDARs that are blocked by APV under some conditions (Chapman \& Chattarji, 2000). In addition, a recent study (Zinebi et al., 2003) has revealed that NMDARs containing the NR2A and 2B subunits are down-regulated in LA after fear conditioning. Hence, NMDAR antagonists with strong affinities for these particular subunits, such as CPP, should be less effective after fear conditioning; our data are consistent with this possibility.

Similar to the effects on the acquisition of Pavlovian fear conditioning, CPP completely blocked the induction of amygdaloid LTP in anesthetized rats without significant effects on baseline synaptic transmission. This finding demonstrates that systemic administration of CPP produces effects on local synaptic plasticity within the amygdala. The strong parallels between the effects of CPP on the acquisition of fear conditioning and the induction of amygdaloid LTP suggest that systemic administration of CPP may have abolished the acquisition of CS-evoked spike firing by preventing the induction of LTP-like plasticity in LA. However, the effects of CPP on the induction of LTP and CS-evoked spike firing were examined in different amygdaloid nuclei (the BLA and LA, respectively). Thus, we are unable to definitively state that the systemic administration of CPP impairs the induction of LTP in LA. Nonetheless, both LA and BLA rely heavily on glutamatergic neurotransmission from afferent fibers (Maren \& Fanselow, 1995; Chapman \& Chattarji, 2000), and the proximity of the structures to each other suggests that diffusion of CPP from the bloodstream likely affected both nuclei. In addition, plasticity in the BLA may be important for the acquisition of fear conditioning (Goosens \& Maren, 2001). Thus, CPP may also affect conditional fear behavior by altering plasticity in the BLA.

The effects of CPP on the acquisition and expression of conditional fear cannot be ascribed to differences in drug state between the time of training and testing. First, we observed a strong asymmetry in the magnitude of the effects of CPP on the acquisition vs. expression of conditional freezing: CPP produced mild deficits in conditional freezing when administered prior to extinction testing, whereas it completely abolished the acquisition of conditional freezing when administered prior to fear conditioning. Similarly, the expression of conditional CS-evoked spike firing in LA and the expression of conditional freezing were differentially affected by CPP. CPP produced a deficit in the behavioral expression of conditional fear without affecting the expression of conditional CS-evoked spike firing. If deficits in fear learning were attributable to state-dependency, the magnitude of CPP-induced deficits should have been similar in both conditions (acquisition and expression), and across all measures (behavioral and electrophysiological). Furthermore, the absence of learning in other paradigms in which animals were trained or tested under the influence of CPP was not due to state-dependency (Kentros et al., 1998) including, importantly, an experiment examining barpress suppression in response to fearful stimuli (Santini et al., 2001).

The effects of CPP on the acquisition and expression of conditional fear also cannot be ascribed to non-associative deficits in either NMDAR-mediated sensory transmission or NMDAR-mediated motor output. The high levels of immediate post-shock freezing observed in rats injected with CPP prior to fear conditioning suggests that CPP does not block sensory transmission of the footshock US, nor does it produce a general inability to express fear behaviors such as freezing. The high levels of CS-evoked freezing exhibited by rats injected with CPP prior to extinction testing indicate that CPP does not block sensory transmission of the auditory CS and, again, confirms that CPP does not prevent behavioral indices of fear per se.

Together, our data suggest that NMDARs make an essential contribution to the associative plasticity that accompanies the acquisition of conditional fear. Because previous studies have revealed that amygdaloid NMDAR blockade is sufficient to prevent associative fear learning, and our data reveal that systemic CPP diffuses into the amygdala in sufficient concentrations to affect synaptic plasticity, it is likely that the acquisition of associative plasticity in the amygdala is blocked by CPP. Nonetheless, we cannot rule out the possibility that NMDAR-mediated associative plasticity outside of the amygdala is also affected by systemic CPP, and that this plasticity is also necessary for the acquisition of fear memory. Our data also reveal that, in the absence of NMDARs, forms of amygdaloid plasticity mediated by nonNMDARs are not sufficient for fear memory formation. Also, NMDAR activation is not necessary for the expression of conditional plasticity in awake, behaving animals or the performance of conditional freezing, both during fear conditioning and during extinction testing. Our data also suggest that NMDARs make a limited contribution to baseline synaptic transmission within the amygdala, but that this is not essential for the expression of conditional behavioral or neuronal plasticity. Thus, we have demonstrated, in vivo, that NMDAR antagonism can affect the acquisition of Pavlovian fear conditioning without significantly affecting routine synaptic transmission or the expression of CS-elicited spike firing. Additional research is needed to clarify the roles of individual NMDAR subunits and other receptor types in mediating fear learning within the amygdala, and to determine whether associative plasticity in LA is sufficient to support fear learning.

\section{Acknowledgements}

This research was supported by a grant from the NIMH (R29MH57865) to S.M. and a Howard Hughes predoctoral fellowship to K.A.G. The authors would like to thank Rodrigo Salazar for technical assistance.

\section{Abbreviations}

APV, D,L-2-amino-5-phosphonovalerate; BLA, basolateral amygdala; CPP, \pm -3-(2-carboxypiperazin-4-yl) propyl-1-phosphonic acid; CR, conditional fear responses; CS, conditioned stimulus; FP, field potential; HFS, high-frequency stimulation; LA, lateral amygdala; LTP, long-term potentiation; NMDARs, $N$-methyl-D-aspartate receptors; PSTH, peri-stimulus time histogram; US, unconditioned stimulus; VAB, ventral angular bundle.

\section{References}

Andine, P., Widermark, N., Axelsson, R., Hyberg, G., Olofsson, U., Martensson, T. \& Sandberg, M. (1999) Characterization of MK801-induced behavior as a putative rat model of psychosis. J. Pharmacol. Exp. Ther, 290, 1393-1408.

Bauer, E.P., Schafe, G.E. \& LeDoux, J.E. (2002) NMDA receptors and 1-type voltage-gated calcium channels contribute to long-term potentiation and different components of fear memory formation in the lateral amygdala. J. Neurosci., 22, 5239-5249.

Blair, H.T., Schafe, G.E., Bauer, E.P., Rodrigues, S.M. \& LeDoux, J.E. (2001) Synaptic plasticity in the lateral amygdala: a cellular hypothesis of fear conditioning. Learn. Mem., 8, 229-242.

Bliss, T.V.P. \& Collingridge, G.L. (1993) A synaptic model of memory: longterm potentiation in the hippocampus. Nature, 361, 31-39.

Campeau, S., Miserendino, M.J.D. \& Davis, M. (1992) Intra-amygdala infusion of the $N$-methyl-D-aspartate receptor antagonist AP5 blocks acquisition but not expression of fear-potentiated startle to an auditory conditioned stimulus. Behav. Neurosci., 106, 569-574.

Chapman, P.F. \& Bellavance, L.L. (1992) Induction of long-term potentiation in the basolateral amygdala does not depend on NMDA receptor activation. Synapse, 11, 310-318.

Chapman, P.F. \& Chattarji, S. (2000) Synaptic plasticity in the amygdala. In Aggleton, J.P. (Ed.), The Amygdala: a Functional Analysis. Oxford University Press, New York, pp. 117-153.

Chapman, P.F., Kairiss, E.W., Keenan, C.L. \& Brown, T.H. (1990) Long-term synaptic potentiation in the amygdala. Synapse, 6, 271-278. 
Fanselow, M.S. \& Kim. J.J. (1994) Acquisition of contextual Pavlovian fear conditioning is blocked by application of an NMDA receptor antagonist D,L-2-amino-5-phosphonovaleric acid to the basolateral amygdala. Behav. Neurosci., 108, 210-212.

Fendt, M. (2001) Injections of the NMDA receptor antagonist aminophosphonopentanoic acid into the lateral nucleus of the amygdala block the expression of fear-potentiated startle and freezing. J. Neurosci., 21, 4111-4115.

Fendt, M. \& Fanselow, M.S. (1999) The neuroanatomical and neurochemical basis of conditioned fear. Neurosci. Biobehav. Rev., 23, 743-760.

Fendt, M. \& Schmid, S. (2002) Metabotropic glutamate receptors are involved in amygdaloid plasticity. Eur. J. Neurosci., 15, 1535-1541.

Gean, P.W., Chang, F.C., Huang, C.C., Lin, J.H. \& Way, L.J. (1993) Long-term enhancement of EPSP and NMDA receptor-mediated synaptic transmission in the amygdala. Brain Res. Bull., 31, 7-11.

Gewirtz, J.C. \& Davis, M. (1997) Second-order fear conditioning prevented by blocking NMDA receptors in amygdala. Nature, 388, 471-474.

Goosens, K.A., Hobin, J. \& Maren, S. (2003) Auditory-evoked spike firing in the lateral amygdala and Pavlovian fear conditioning: mnemonic code or fear bias? Neuron, 40, 1013-1022.

Goosens, K.A. \& Maren, S. (2001) Contextual and auditory fear conditioning are mediated by the lateral, basal, and central amygdaloid nuclei in rats. Learn. Mem., 8, 148-155.

Goosens, K.A. \& Maren, S. (2002) Long-term potentiation as a substrate for memory: evidence from studies of amygdaloid plasticity and Pavlovian fear conditioning. Hippocampus, 12, 592-599.

Goosens, K.A. \& Maren, S. (2003) Pretraining NMDA receptor blockade in the basolateral complex, but not the central nucleus, of the amygdala prevents savings of conditional fear. Behav. Neurosci., 117, 738-750.

Greba, Q. \& Kokkinidis, L. (2000) Peripheral and intraamygdalar administration of the dopamine D1 receptor antagonist SCH 23390 blocks fearpotentiated startle but not shock reactivity or the shock sensitization of acoustic startle. Behav. Neurosci., 114, 262-272.

Guarraci, F.A., Frohardt, R.J., Falls, W.A. \& Kapp, B.S. (2000) The effects of intra-amygdaloid infusions of a D2 dopamine receptor antagonist on Pavlovian fear conditioning. Behav. Neurosci., 114, 647-651.

Hrabetova, S. \& Sacktor, T.C. (1997) Long-term potentiation and long-term depression are induced through pharmacologically distinct NMDA receptors. Neurosci. Lett., 226, 107-110.

Huang, Y.Y. \& Kandel, E.R. (1998) Postsynaptic induction and PKAdependent expression of LTP in the lateral amygdala. Neuron, 21, 169-178.

Kentros, C., Hargreaves, E., Hawkins, R.D., Kandel, E.R., Shapiro, M. \& Muller, R.V. (1998) Abolition of long-term stability of new hippocampal place cell maps by NMDA receptor blockade. Science, 280, 2121-2126.

Kim, M., Campeau, S., Falls, W.A. \& Davis, M. (1993) Infusion of the nonNMDA receptor antagonist CNQX into the amygdala blocks the expression of fear-potentiated startle. Behav. Neural Biol., 59, 5-8.

Kim, J.J., DeCola, J.P., Landeira-Fernandez, J. \& Fanselow, M.S. (1991) $N$-methyl-D-aspartate receptor antagonist APV blocks acquisition but not expression of fear conditioning. Behav. Neurosci., 105, 126-133.

Kim, J.J., Fanselow, M.S., DeCola, J.P. \& Landeira-Fernandez, J. (1992) Selective impairment of long-term but not short-term conditional fear by the $N$-methyl-D-aspartate antagonist APV. Behav. Neurosci., 106, 591-596.

LeDoux, J.E. (2000) Emotion circuits in the brain. Annu. Rev. Neurosci., 23, $155-184$

Lee, H.J., Choi, J.S., Brown, T.H. \& Kim, J.J. (2001) Amygdalar N-methyl-Daspartate receptors are critical for the expression of multiple conditioned fear responses. J. Neurosci., 21, 4116-4124.

Lee, H.J. \& Kim, J.J. (1998) Amygdalar NMDA receptors are critical for new fear learning in previously fear-conditioned rats. $J$. Neurosci. 18, 8444-8454.

Li, X.F., Phillips, R. \& LeDoux, J.E. (1995) NMDA and non-NMDA receptors contribute to synaptic transmission between the medial geniculate body and the lateral nucleus of the amygdala. Exp. Brain Res., 105, 87-100.

Li, X.F., Stutzmann, G.E. \& LeDoux, J.E. (1996) Convergent but temporally separated inputs to lateral amygdala neurons from the auditory thalamus and auditory cortex use different postsynaptic receptors: in vivo intracellular and extracellular recordings in fear conditioning pathways. Learn. Mem., 3, 229 242.

Mahanty, N.K. \& Sah, P. (1999) Excitatory synaptic inputs to pyramidal neurons of the lateral amygdala. Eur. J. Neurosci., 11, 1217-1222.

Malenka, R.C. \& Nicoll, R.A. (1999) Long-term potentiation - a decade of progress? Science, 285, 1870-1874.
Maren, S. (1999) Long-term potentiation in the amygdala: a mechanism for emotional learning and memory. Trends Neurosci., 22, 561-567.

Maren, S. (2000) Auditory fear conditioning increases CS-elicited spike firing in lateral amygdala neurons even after extensive overtraining. Eur. J. Neurosci., 12, 4047-4054.

Maren, S. (2001) Neurobiology of Pavlovian fear conditioning. Ann. Rev. Neurosci., 24, 897-931.

Maren, S., Aharonov, G., Stote, D.L. \& Fanselow, M.S. (1996) N-methyl-Daspartate receptors in the basolateral amygdala are required for both acquisition and expression of conditional fear in rats. Behav. Neurosci., 10, 1365-1374.

Maren, S. \& Baudry, M. (1995) Properties and mechanisms of long-term synaptic plasticity in the mammalian brain: relationships to learning and memory. Neurobiol. Learn. Mem., 63, 1-18.

Maren, S. \& Fanselow, M.S. (1995) Synaptic plasticity in the basolateral amygdala induced by hippocampal formation stimulation in vivo. J. Neurosci., 15, 7548-7564.

Miserendino, M.J.D., Sananes, C.B., Melia, K.R. \& Davis, M. (1990) Blocking of acquisition but not expression of conditioned fear-potentiated startle by NMDA antagonists in the amygdala. Nature, 345, 716-718.

Paré, D. \& Gadreau, H. (1996) Projections cells and interneurons of the lateral and basolateral amygdala: distinct firing patterns and differential relation to theta and delta rhythms in conscious cats. J. Neurosci., 16, 3334-3350.

Quirk, G.J., Armony, J.L. \& LeDoux, J.E. (1997) Fear conditioning enhances different temporal components of CS-evoked spike trains in auditory cortex and lateral amygdala. Neuron, 19, 613-624.

Quirk, G.J., Repa, J.C. \& LeDoux, J.E. (1995) Fear conditioning enhances short-latency auditory responses of lateral amygdala neurons: parallel recordings in the freely behaving rat. Neuron, 15, 1029-1039.

Repa, J.C., Muller, J., Apergis. J., Desrochers, T.M., Zhou, Y. \& LeDoux, J.E. (2001) Two different lateral amygdala cell populations contribute to the initiation and storage of memory. Nature Neurosci., 4, 724-731.

Rodrigues, S.M., Bauer, E.P., Farb, C.R., Schafe, G.E. \& LeDoux, J.E. (2002) The group I metabotropic glutamate receptor mGluR5 is required for fear memory formation and long-term potentiation in the lateral amygdala. J. Neurosci., 22, 5219-5229.

Rodrigues, S.M., Schafe, G.E. \& LeDoux, J.E. (2001) Intra-amygdala blockade of the NR2B subunit of the NMDA receptor disrupts the acquisition but not the expression of fear conditioning. J. Neurosci., 21, 6889-6896.

Rogan, M.T., Staubli, U.V. \& LeDoux, J.E. (1997) AMPA receptor facilitation accelerates fear learning without altering the level of conditioned fear acquired. J. Neurosci., 17, 5928-5935.

Romanski, L.M. \& LeDoux, J.E. (1992) Equipotentiality of thalamo-amygdala and thalamo-cortico-amygdala circuits in auditory fear conditioning. J. Neurosci., 12, 4501-4509.

Rosenkranz, J.A. \& Grace, A.A. (2002) Dopamine-mediated modulation of odour-evoked amygdala potentials during pavlovian conditioning. Nature, 417, 282-287.

Santini, E., Muller, R.U. \& Quirk, G.J. (2001) Consolidation of extinction learning involves transfer from NMDA-independent of NMDA-dependent memory. J. Neurosci., 21, 9009-9017.

Swanson, L.W. (1999) Brain maps: Structure of the Rat Brain, 2nd Edn. Elsevier, Amsterdam.

Walker, D.L. \& Davis, M. (1997) Double dissociation between the involvement of the bed nucleus of the stria terminalis and the central nucleus of the amygdala in startle increases produced by conditioned versus unconditioned fear. J. Neurosci., 17, 9375-9383.

Watkins, J.C. \& Olverman, H.J. (1987) Agonists and antagonists for excitatory amino acid receptors. Trends Neurosci., 10, 265-272.

Weisskopf, M.G., Bauer, E.P. \& LeDoux, J.E. (1999) L-Type voltage-gated calcium channels mediate NMDA-independent associative long-term potentiation at thalamic input synapses to the amygdala. J. Neurosci., 19, $1019-1033$.

Weisskopf, M.G. \& LeDoux, J.E. (1999) Distinct populations of NMDA receptors at subcortical and cortical inputs to principal cells of the lateral amygdala. J. Neurophysiol., 81, 930-934.

Zinebi, F., Xie, J., Liu, J., Russell, R.T., Gallagher, J.P., McKernan, M.G. \& Shinnick-Gallagher, P. (2003) NMDA currents and receptor protein are downregulated in the amygdala during maintenance of fear memory. J. Neurosci., 23, 10283-10291. 